\title{
The Unforeseen Influence of Parents' Socialization Behaviors on the Social Adjustment of Children with Intellectual Disabilities
}

\author{
Emilie Jacobs, Stéphanie Mazzone, Poline Simon, Nathalie Nader-Grosbois \\ Psychological Sciences Research Institute, UCLouvain, Louvain-la-Neuve, Belgium \\ Email: emilie.jacobs@uclouvain.be,nathalie.nader@uclouvain.be
}

How to cite this paper: Jacobs, E., Mazzone, S., Simon, P., \& Nader-Grosbois, N. (2019). The Unforeseen Influence of Parents' Socialization Behaviors on the Social Adjustment of Children with Intellectual Disabilities. Psychology, 10, 1275-1301. https://doi.org/10.4236/psych.2019.109083

Received: March 7, 2019

Accepted: July 20, 2019

Published: July 23, 2019

Copyright $\odot 2019$ by author(s) and Scientific Research Publishing Inc. This work is licensed under the Creative Commons Attribution International License (CC BY 4.0).

http://creativecommons.org/licenses/by/4.0/

\begin{abstract}
This paper investigates how parents of children with intellectual disabilities (IDs) socialize emotions, and how these behaviors affect their children's social adjustment. The goals were: 1 ) to identify the emotion-related socialization behaviors (ERSBs) used by parents of children with IDs, in comparison to parents of typically developing (TD) children, and 2) to examine the extent to which these reactions and conversations affect children's social competences and (mal)adjustment. Parents' reactions to emotions have been described as either supportive or unsupportive of children's socio-Emotional development, and their conversations about emotions with their children have also been considered as helpful in this respect. However, little is known about these reactions and conservations in either mothers or fathers of children with IDs. The first study compared these ERSBs in 54 mothers and 32 fathers of children of preschool developmental age with or without IDs. The results showed that parents of children with IDs use more unsupportive reactions to their emotions. The second study investigated the links between parents' reactions and conversations, and their children's profiles (IDs, developmental age, social adjustment and externalizing or internalizing problems). Correlational and regression analyses emphasized specific links between some maternal or paternal reactions and conversations on the one hand and children's characteristics, social adjustment or behavior problems on the other hand.
\end{abstract}

\section{Keywords}

Parental Emotion-Related Socialization Behaviors, Emotion-Related Conversations, Intellectual Disabilities, Social Adjustment, Behavioral Problems 


\section{Introduction}

Over the past two decades, ERSBs in parents of TD preschoolers have been studied with reference to the heuristic model of the socialization of emotions developed by Eisenberg, Cumberland and Spinrad (1998). This model describes ERSBs as parents' reactions to their children's emotions, their emotion-related conversations and their emotional expressiveness. Hypotheses and empirical studies have revealed a dichotomous view of these parental behaviors, which divides parental behaviors according to children's negative or positive emotions and two categories: supportive or unsupportive (Eisenberg et al., 1998; Eisenberg, Fabes, \& Murphy, 1996; Fabes, Poulin, Eisenberg, \& Madden-Derdich, 2002). Parents can react to children's negative emotions either supportively, by giving comfort, offering a problem-focused response and expressing encouragement, or unsupportively, by showing distress, punishing or minimizing the significance of the cause of the child's emotions. They can react to children's positive emotions with either supportive responses such as socialization and encouragement, or unsupportive responses such as reprimand and discomfort.

Some of these parental behaviors have been found to affect children's social adjustment (e.g. Eisenberg et al., 1998; Eisenberg et al., 1996; Fabes, Leonard, Kupanoff, \& Martin, 2001; Gottman, Katz, \& Hooven, 1996; Jones, Eisenberg, Fabes, \& MacKinnon, 2002). Unsupportive and supportive parental reactions to negative emotions have been associated with better or poorer social competences in children respectively (Fabes et al., 2001; Jones et al., 2002). Children whose parents' reactions to and conversations about emotions are unsupportive are at greater risk of inhibition, or externalizing and internalizing behavior problems (e.g. Chorpita \& Barlow, 1998; Degnan, Almas, \& Fox, 2010; Dodge \& Pettit, 2003; Hudson \& Rapee, 2001). Concerning the impact of parents' gender on ERSBs, a few studies have emphasized that fathers of TD preschoolers display more unsupportive reactions such as minimizing and punishing than mothers (Eisenberg et al., 1998; Eisenberg et al., 1996). Therefore, children are affected by both parents' behaviors in their social development.

Several studies have shown that ERSBs vary according to parents' characteristics, such as chronological age (Mazzone \& Nader-Grosbois, 2017b), gender (Wong, McElwain, \& Halberstadt, 2009), and beliefs (Eisenberg et al., 1998; Wong et al., 2009). They also differ according to individual characteristics of children, such as chronological age (Denham, Bouril, \& Belouad, 1994; Eisenberg et al., 1999; Fabes et al., 1994; Lagattuta \& Wellman, 2002), developmental age (Eisenberg et al., 1998; Mazzone \& Nader-Grosbois, 2017b), gender (Casey \& Fuller, 1994; Eisenberg et al., 1998), personality (Mazzone \& Nader-Grosbois, 2017b), and the presence of a developmental disorder (Mazzone \& Nader-Grosbois, 2017a; Rodas, Zeedyk, \& Baker, 2016).

Surprisingly, only a few studies have investigated socialization behaviors in parents of children with developmental disabilities, including autistic spectrum disorder (Bougher-Muckian, Root, Coogle, \& Floyd, 2016; Mazzone \& Nader-Grosbois, 2017b) or intellectual disabilities (Phillips, Conners, \& Curtner-Smith, 
2017; Rodas, Chavira, \& Baker, 2017; Rodas et al., 2016). However, given the impairments in adaptive functioning in children with IDs, parental ERSBs need to be investigated in this population.

\subsection{Parenting Children with Intellectual Disabilities}

Some authors have reported that parents of children with IDs demonstrate more negative parenting, in comparison to TD samples (McIntyre, 2008; Phillips et al., 2017; Rodas et al., 2016), but these outcomes depend on the measure (self-reported vs. observational). Moreover, the results of these studies have focused only on reactions to negative emotions.

More precisely, McIntyre (2008) has shown through an observational measure that these parents demonstrate more negative interactions with their children during unstructured activities, whereas Rodas, Chavira and Baker (2017) did not observe any negative parenting during a naturalistic home observation. Yet, in the same study, Rodas, Chavira and Baker (2017), assessed also parenting with a self-report measure, the Coping with Children's Negative Emotions Scale (Fabes, Eisenberg, \& Bernzweig, 1990). Through this questionnaire, parents reported more unsupportive reactions to their children's negative emotions than parents of TD children. Recently, Phillips, Conners and Curtner-Smith (2017) investigated mothers' behaviors toward their children with Down syndrome, by means of the Parenting Style and Dimensions Questionnaire (Robinson, Mandleco, Olsen, \& Hart, 2001). These mothers reported a more permissive and less authoritative style than mothers of TD children did. Moreover, mothers of children with Down syndrome ignored maladaptive behaviors more often and used less reasoning or verbal hostility than mothers of TD children (Phillips et al., 2017).

Another important observation came from the comparison of mothers and fathers of children with and without IDs. Rodas et al. (2016) found that mothers of children with IDs demonstrated a higher level of unsupportive reactions than fathers, during an observational measure. However, with a self-reported measure, fathers mentioned more unsupportive reactions than mothers (Rodas et al., 2016), and mothers reported more supportive reactions than fathers (Rodas et al., 2017). These studies of Rodas et al. $(2016,2017)$ reveal the importance of taking both mothers and fathers into account in ERSB-related research, as observations indicate that mothers and fathers may use diverse ERSBs strategies with potentially differentiated impacts in particular on children's social development and adjustment.

\subsection{Social (Mal)Adjustment Profile of Children with IDs}

Social development, including social adjustment, is impaired in children with IDs (Baurain \& Nader-Grosbois, 2013; Kasari \& Bauminger, 1998; Nader-Grosbois, Houssa, \& Mazzone, 2013; Thirion-Marissiaux \& Nader-Grosbois, 2008). Beyond intellectual limitations, restrictions in adaptive functioning have been recognized as diagnostic criteria of IDs (AAIDD, 2011). People close to 
children with IDs report difficulties in social competences affecting their relationships, at home and school. These children appear less autonomous, in comparison with TD children, at preschool and school age (Crnic, Hoffman, Gaze, \& Edelbrock, 2004; Keogh, Bernheimer, Daley, \& Haney, 1989; Merrell \& Holland, 1997; Zion \& Jenvey, 2006). It has often been observed that they are dependent in their relationship with their parents, displaying reduced autonomous behaviors in daily life. Children with IDs are also described as having less prosocial and more egocentric behaviors (Thirion-Marissiaux \& Nader-Grosbois, 2008). Their social deficits are also reflected in various behavioral manifestations. They tend to display externalizing (Baker, Neece, Fenning, Crnic, \& Blacher, 2010; Taylor, 2002) or internalizing problems (Merrell \& Holland, 1997; Thirion-Marissiaux \& Nader-Grosbois, 2008), or even both (Baker et al., 2003; Dekker \& Koot, 2003; Dekker, Koot, Ende, \& Verhulst, 2002; Emerson, 2003; Nader-Grosbois et al., 2013). Externalizing behaviors are manifested in resistant or oppositional behaviors to others that impede cooperative and positive interactions, as well as exhibiting anxiety or isolation that limits social opportunities and inclusion. Adolescents with IDs are at greater risk than TD adolescents of feeling loneliness, isolation, rejection and social dissatisfaction (Gascon, Bibeau, Grondin, \& Milot, 2010), which are expressions of internalizing behaviors. Despite these observations, less is known about internalizing behaviors in children with IDs and more investigation is needed in this area (Hauser-Cram \& Woodman, 2016). These studies focusing on social maladjustment in children with IDs have mainly assessed it by using the Child Behavior Checklist (Achenbach \& Edelbrock, 1991), while few have explored the strengths and weaknesses of children with IDs in terms of their social adjustment profiles. These results have therefore embodied a deficient approach. While in TD populations, it is well-known that behavior problems are associated with negative parental strategies (e.g. Dodge \& Pettit, 2003; McKee et al., 2007; Rubin \& Mills, 1991), the impact of ERSBs on the social adjustment of children with IDs has received limited attention in the literature.

\subsection{Effects of Parenting on Social (Mal)Adjustment Profile of Children with IDs}

Recently, studies have concluded that unsupportive parental behaviors are related to conduct problems in children with IDs (Paczkowski \& Baker, 2007). These parents use fewer positive parenting practices and more physical punishment when their children present borderline IDs and externalizing behaviors, compared to parents of children without these behavior problems (Schuiringa, van Nieuwenhuijzen, Orobio de Castro, \& Matthys, 2015). Rodas et al. (2016) noticed that children with IDs are at heightened risk of internalizing problems if their father is depressed and uses unsupportive parenting practices. Surprisingly, internalizing problems at the age of eight are also explained by supportive maternal parenting at the age of four (Rodas et al., 2017). This last finding adds to 
the evidence suggesting that beyond supportive or unsupportive parenting, what is important is an adapted use of ERSBs. Likewise, in a study of parents of children with autistic spectrum disorder, Mazzone and Nader-Grosbois (2017a) emphasize the interest of exploring each reaction, instead of using the dichotomous classification of supportive and unsupportive reactions and conversations. In fact, in their study, comforting and encouragement reactions are observed to be unsupportive for children with autistic spectrum disorder. These studies underline the interest of taking both children's and parents' individual characteristics in exploring ERSBs.

\subsection{Objectives of the Studies}

The literature review highlights a lack of information in previous research about ERSBs of mothers and fathers of children with IDs. No studies including a measure of parenting reactions to children's positive emotions were found. Therefore, in a first study, we aimed to identify the specific characteristics of mothers and fathers' reactions to and conversations about negative and positive emotions felt by their children with IDs, in comparison with those of the parents of TD children.

Moreover, in view of the difficulties with social adjustment and the behavioral problems of children with IDs and the potential impact of ERSBs, the link between ERSBs on children with IDs' social adjustment needs to be explored. To date, most studies have investigated this relation between externalizing or internalizing problems and parents' behaviors in response to children's negative emotions. To respond to these limitations, the aim of the second study was to examine links between reactions and conversations of mothers and fathers and the social adjustment profiles of their children with IDs, by considering their social competences and their externalizing and internalizing problems. The study aimed to assess the variability in their profiles in terms of the respective contribution of individual characteristics and parental ERSBs.

It was hoped that a better understanding of these mothers' and fathers' ERSBs and of their influence on their children's profiles could provide useful input for adapted and specific prevention and intervention programs for parents of children with IDs.

\section{Study 1: Comparison of Emotion-Related Socialization Behaviors between Parents of Children with and without Intellectual Disabilities}

\subsection{Method}

The methodology of this research is described below, describing participants, procedure and measures.

\subsubsection{Participants}

Fifty-four mothers and thirty-two fathers of children with and without IDs were 
recruited. In each of the two groups (parents of children with IDs and parents of TD children), there were 27 mothers and 16 fathers, and 20 boys and 7 girls. Children were matched for gender and global developmental age whereas parents were matched for gender and education level, whenever possible. All children with intellectual disabilities had been diagnosed according to AAIDD and DSM-V criteria, displaying limitations in intellectual functioning and in adaptive behavior and presenting a non-specific intellectual disability and an intellectual quotient between 50 and 70. Children with Williams syndrome or Autistic Spectrum Disorder were excluded. The TD children were a subsample from a longitudinal study published by Mazzone and Nader-Grosbois (2017b). In addition, all children had a preschool developmental age. Those with IDs had a mean global developmental age (GDA) of 59.26 months $(S D=16.24)$, ranging from 38 to 88 months, whereas the TD children had a mean GDA of 58.31 months ( $S D=$ 16.05), ranging from 37 to 97 months. In terms of chronological age, the children with IDs had a mean age of 103.15 months ( $S D=24.87$ ), ranging from 55 to 145 months, while the TD children had a mean age of 55.66 months ( $S D=9.89)$, ranging from 41 to 71 months. The participants were recruited in French-speaking Belgian schools and specialized schools for children with IDs.

The educational level of the parents was as follows: 1) for parents of TD children, $18.5 \%$ of mothers and $12.5 \%$ of fathers had completed secondary school; $55.6 \%$ of mothers and $62.5 \%$ of fathers had completed a non-university higher education program; and 25.9 of mothers and $25 \%$ of fathers had completed a university degree program; 2) for parents of children with IDs, $29.6 \%$ of mothers and $31.4 \%$ of fathers had not completed primary school; $37.1 \%$ of mothers and $25 \%$ of fathers had completed primary school; $14.8 \%$ of mothers and $6.2 \%$ of fathers had completed special elementary school; $7.4 \%$ of mothers and none of the fathers had completed secondary school; $7.4 \%$ of mothers and $12.5 \%$ of fathers had completed special secondary school; none of the mothers and $18.7 \%$ of fathers had completed an apprenticeship; and $3.7 \%$ of mothers and $6.2 \%$ of fathers had completed a non-university higher education program.

\subsubsection{Procedure}

Firstly, parents received an information letter about the project, and, if interested, completed consent forms for their own participation and that of their child. The letter and the form informed parents that all collected information would be kept anonymous and that they could withdraw at any time. All children were tested at their school (a specialized school for children with IDs) by experienced psychology researchers or by trained students in psychology. Parents completed the questionnaire alone at home or during a moment with a researcher.

\subsubsection{Measures}

\section{Assessment of children}

Wechsler Preschool and Primary Scales (WPPSI-III; Wechsler, 2004). We used these scales to measure the cognitive functioning and GDA of each child. 
Four subtests, namely "information", "vocabulary", "block design" and "matrix reasoning", were administered in a quiet room at school. Each child had to have mild to moderate intellectual disabilities and a preschool GDA. These subtests were therefore used only during the pretest session.

\section{Questionnaires completed by parents about themselves}

Parental Reactions toward Positive and Negative Emotions (Daffe \& Nader-Grosbois, 2009). This questionnaire is an integrated version of two other questionnaires, namely Questionnaire sur les Réactions Parentales aux Emotions Positives Exprimées (QRPEPE, Ladouceur, Reid, \& Jacques, 2002) and Coping with Children's Negative Emotion Scale (CCNES, Fabes, Poulin, Eisenberg, \& Madden-Derdich, 2002; French version, Coutu, Debeau, Provost, Royer, \& Lavigueur, 2002). Eight hypothetical scenarios are included in this questionnaire in which a child feels negative emotions (fear, sadness and anger) or positive emotion (joy). For the scenarios related to negative emotions, six parental reactions are evaluated: comforting response, encouragement of emotional expression, problem-focused responses, distress, minimizing and punitive response. For the positive scripts, reprimand, discomfort, socialization and encouragement are the four parental reactions evaluated. On a 7-point Likert scale ranging from "very unlikely" to "very likely", parents indicate to what extent they use different strategies to support or repress their child's emotions. The factor analysis of this questionnaire, validated on 328 parents of TD children, highlighted two subscales, namely supportive reactions and unsupportive reactions for positive and negative emotions. A score for each parental reaction and a score for supportive and unsupportive reactions can therefore be obtained. Cronbach's alpha is 0.78 and 0.81 for negative scenarios and 0.77 and 0.62 for the joy scripts.

Questionnaire of Parent-Child Conversations about Emotions (QCPEE, Mazzone, Roskam, Mikolajczak, \& Nader-Grosbois, 2017). This questionnaire assesses, based on a continuum, if parents' conversations with their children are more supportive or unsupportive. It contains three parts. In the first part, parents are asked to rank five domains in order of priority for their child, including affective and social domains. They are also asked to what extent they agree or disagree with a number of preliminary statements about emotions, such as, "In general, I ask my child questions about his or her emotions (joy, sadness, fear, anger)". The second part contains 24 items depicting emotion-related conversations between parents and their child. These situations address the supportive or unsupportive strategies that parents can use in conversations with their child. Parents indicate the frequency of the situation during the last two weeks on a 4-point scale ranging from "not at all" to " 5 or more times". As each items described a specific situation, a "not applicable" response is also possible if this situation did not happen during the last two weeks. In the third part, parents are shown a list of emotional verbs and terms related to the four basic emotions. They are asked to indicate which terms they use with their child. The factor analysis of this questionnaire, validated on 300 parents, identifies a single factor. 
Conversely, items assessing unsupportive strategies are reversed. Cronbach's alpha is 0.91 for the unique score.

\subsection{Results}

\subsubsection{Preliminary Analyses}

Table 1 presents the descriptive statistics and the comparison of the sample with and without IDs. The children had approximately the same developmental age and there was no difference in the gender composition of the two groups. However, the children with IDs were significantly older than the TD children. Concerning the parents, there was a difference in mothers' educational level between the two groups: mothers of TD children had a higher level of education.

\subsubsection{Between-Groups Comparison of Mothers' and Fathers' Reactions} Table 2 presents the results of the independent samples $t$-test for the betweengroups comparison.

For mothers, a difference with regard to global score of unsupportive reactions to children's negative emotions was observed ( $t=5.75 ; p<0.001 ; d=1.58$ ). Looking at the different reactions in this global score, results showed that mothers of children with IDs displayed a higher level of distress $(t=2.67 ; p<0.05 ; d=$ $0.72)$ and in particular used more punitive $(t=5.33 ; p<0.001 ; d=1.45)$ and $\mathrm{mi}-$ nimizing $(t=5.54 ; p<0.001 ; d=1.51)$ responses, when faced with negative emotions in their children. No difference was obtained regarding the others global supportive or unsupportive scores (namely supportive reactions to negative emotions, supportive reactions to positive emotions and unsupportive reactions to positive emotions). Nevertheless, we noticed some disparities between parents when we look at differences between reactions itself. Mothers of children with IDs presented more comforting reactions $(t=2.63 ; p<0.05 ; d=0.73)$ to negative emotions and tended to feel more discomfort $(t=2.01 ; p<0.05 ; d=$ $0.55)$ in response to positive emotions. Mothers of TD children were more likely to discuss emotions than mothers of children with IDs $(t=-2.31 ; p<0.05 ; d=$ 0.65). More precisely, mothers of children with IDs used fewer terms related to anger $(t=-2.67 ; p<0.01 ; d=0.87)$.

Table 1. Means and standard deviations of participants' characteristics in Study 1.

\begin{tabular}{ccccccc}
\hline & & \multicolumn{2}{c}{ IDs sample } & \multicolumn{2}{c}{ TD sample } & \multirow{2}{*}{$X 2 / t$} \\
\cline { 3 - 5 } & $M$ & $S D$ & $M$ & $S D$ & \\
\hline Mothers' characteristics & & & & & \\
$\begin{array}{c}\text { Educational level (max 8) } \\
\text { Fathers' characteristics }\end{array}$ & 3.7 & 2.75 & 5.29 & 1.37 & $2.53^{*}$ \\
$\begin{array}{c}\text { Educational level (max 8) } \\
\text { Children's characteristics }\end{array}$ & 4.08 & 3.31 & 5.4 & 1.12 & 0.28 \\
$\quad$ Gender (\% male) & & & & & \\
Age (in months) & Chronological age & 103.15 & 24.87 & 55.66 & 9.89 & $9.26^{* * *}$ \\
& Developmental age & 59.26 & 16.24 & 58.31 & 16.05 & 0.22 \\
\hline
\end{tabular}

Notes. $M=$ mean, $S D=$ standard deviation, TD = Typically Developing, IDs = Intellectual Disabilities, ${ }^{\star} p<$ $0.05,{ }^{* *} p<0.01 ;{ }^{* * *} p<0.000$. 
Table 2. Independent sample t-test of parental reactions.

\begin{tabular}{|c|c|c|c|c|}
\hline & TD children & Children with IDs & \multirow{2}{*}{$t$} & \multirow{2}{*}{$d$} \\
\hline & $M(S D)$ & $M(S D)$ & & \\
\hline \multicolumn{5}{|l|}{ Mothers' reactions $(n=27)$} \\
\hline SUR_-E & $5.16(0.55)$ & $5.23(0.78)$ & 0.39 & \\
\hline Comforting & $5.04(0.78)$ & $5.62(0.81)$ & $2.63^{*}$ & 0.73 \\
\hline Problem-focused & $5.81(0.74)$ & $5.54(0.91)$ & -1.18 & \\
\hline Encouragement of expression of emotion & $4.64(1)$ & $4.55(1.11)$ & -0.31 & \\
\hline NSUR_-E & $2.59(0.58)$ & $3.88(1)$ & $5.75^{\star * *}$ & 1.58 \\
\hline Distress & $2.30(0.63)$ & $3.05(1.32)$ & $2.67^{\star}$ & 0.72 \\
\hline Punitive & $1.86(0.62)$ & $3.50(1.47)$ & $5.33^{* * *}$ & 1.45 \\
\hline Minimizing responses & $3.63(1.08)$ & $5.12(0.88)$ & $5.54^{* * *}$ & 1.51 \\
\hline SUR_+E & $4.94(0.85)$ & $5.09(1.09)$ & 0.55 & \\
\hline Socialization & $5.31(1.50)$ & $5.50(1.62)$ & 0.43 & \\
\hline Encouragement & $4.57(1.49)$ & $4.68(1.52)$ & 0.27 & \\
\hline NSUR_+E & $2.90(1.08)$ & $3.54(1.50)$ & 1.81 & \\
\hline Reprimand & $3.64(1.37)$ & $4.22(1.82)$ & 1.31 & \\
\hline Discomfort & $2.16(1.16)$ & $2.88(1.45)$ & $2.01^{*}$ & 0.55 \\
\hline \multicolumn{5}{|l|}{ Mothers' conversations $(n=27)$} \\
\hline QCPEE & $2.49(0.41)$ & $2.16(0.59)$ & $-2.31^{\star}$ & 0.65 \\
\hline Joy-related terms & $5.42(1.86)$ & $5.73(3.47)$ & 0.37 & \\
\hline Anger-related terms & $4.23(1.11)$ & $2.91(1.82)$ & $-2.67^{\star \star}$ & 0.87 \\
\hline Sadness-related terms & $1.62(1.27)$ & $1.86(1.24)$ & 0.64 & \\
\hline Fear-related terms & $1.28(1.31)$ & $1(1.60)$ & -0.66 & \\
\hline Emotion-related verbs & $1.79(1.67)$ & $1.77(1.69)$ & -0.04 & \\
\hline \multicolumn{5}{|l|}{ Fathers' reactions $(n=16)$} \\
\hline SUR_-E & $4.49(0.72)$ & $5.39(0.95)$ & $3.01^{\star \star}$ & 1.07 \\
\hline Comforting & $4.63(0.84)$ & $5.60(0.86)$ & $3.21^{\star \star}$ & 1.14 \\
\hline Problem-focused & $4.91(0.86)$ & $5.74(1.20)$ & $2.22^{*}$ & 0.79 \\
\hline Encouragement of expression of emotion & $3.93(1.06)$ & $4.86(1.14)$ & $2.37^{*}$ & 0.84 \\
\hline NSUR_-E & $2.94(0.47)$ & $3.83(1.33)$ & $2.52^{*}$ & 0.89 \\
\hline Distress & $2.25(0.56)$ & $3.39(1.50)$ & $2.83^{\star *}$ & 1.01 \\
\hline Punitive & $2.39(0.79)$ & $3.25(1.58)$ & 1.94 & \\
\hline Minimizing responses & $4.15(0.78)$ & $4.84(1.14)$ & 1.99 & \\
\hline SUR_+E & $4.78(0.80)$ & $5.39(1.06)$ & 1.83 & \\
\hline Socialization & $5.25(1.21)$ & $5.68(1.43)$ & 0.93 & \\
\hline Encouragement & $4.31(1.19)$ & $5.09(1.50)$ & 1.62 & \\
\hline NSUR_+E & $2.87(0.99)$ & $3.75(1.48)$ & 1.96 & \\
\hline
\end{tabular}


Continued

\begin{tabular}{ccccc}
\hline Reprimand & $3.90(1.64)$ & $4.43(1.61)$ & 0.92 & \\
Discomfort & $1.84(0.96)$ & $3.06(2)$ & $2.19^{*}$ & 0.78 \\
Fathers' conversations $(n=16)$ & & & & \\
QCPEE & $2.33(0.29)$ & $2.20(0.82)$ & -0.57 & \\
Joy-related terms & $5.53(3.33)$ & $3.75(4.71)$ & -1.15 & \\
Anger-related terms & $4.27(2.58)$ & $2.92(3.26)$ & -1.20 & \\
Sadness-related terms & $2(1.73)$ & $2.25(2.83)$ & 0.28 & \\
Fear-related terms & $1.42(1.24)$ & $1.33(2.53)$ & -0.10 & \\
Emotion-related verbs & $2.07(1.68)$ & $1.17(1.89)$ & -1.29 & \\
\hline
\end{tabular}

Notes. $\mathrm{M}=$ mean, $\mathrm{SD}=$ standard deviation, $\mathrm{SUR}=$ supportive reactions, $\mathrm{NSUR}=$ unsupportive reactions, $-\mathrm{E}=$ negative emotion, $+\mathrm{E}=$ positive emotion, $\mathrm{TD}=$ typically Developing, $\mathrm{IDs}=$ intellectual disabilities, ${ }^{*} p$ $<0.05,{ }^{* *} p<0.01 ;{ }^{* *} p<0.001$.

Fathers of children with IDs displayed more supportive $(t=3.01 ; p<0.01 ; d=$ $1.07)$ and unsupportive $(t=2.52 ; p<0.05 ; d=0.89)$ reactions to negative emotions. More precisely, in response to their children's negative emotions, they displayed more supportive reactions such as comforting $(t=3.21 ; p<0.01 ; d=$ 1.07), problem-focused ( $t=2.22 ; p<0.05 ; d=0.79)$ and encouragement of expression $(t=2.37 ; p<0.05 ; d=0.84)$, but also showed more distress $(t=2.83 ; p$ $<0.01 ; d=1.01)$, than fathers of TD children. When children with IDs demonstrated positive emotions, their fathers felt more discomfort $(t=2.19 ; p<0.05 ; d$ $=0.78$ ) - an unsupportive reaction. No difference was observed in discussions of emotions between fathers of children with and without IDs.

\section{Study 2: Parents' Emotion-Related Behaviors and Social (Mal)Adjustment of Children with Intellectual Disabilities}

\subsection{Method}

The methodology of this research is described below, describing participants, procedure and measures.

\subsubsection{Participants}

The participants were the 20 boys and 7 girls with IDs and their parents (27 mothers and 16 fathers) from Study 1 . The inclusion and exclusion criteria, and hence the individual characteristics of the parents and children, were the same as in Study 1.

\subsubsection{Procedure}

As for Study 1, parents and their children only took part in the research process after providing their consent. All children were tested in a quiet room at school by experienced psychology researchers or trained students in psychology. Parents completed the questionnaire alone at home or during a moment with a researcher.

\subsubsection{Measures}

In addition to those mentioned in Study 1, parents completed the following measures. 
Social Adjustment scales for children (EASE, Hughes, Soares-Boucaud, Hochman, \& Frith, 1997). This 50-item questionnaire assesses adults' perceptions of children's socio-Emotional adjustment. Parents estimate the frequency of certain behaviors in daily interactions, using a 2-point Likert scale, with three choices "very rare", "frequent", "usual" Half of the items measure social skills such as politeness, discipline or civility, and provide an "EASE Social Skills" score. The other half evaluate social skills related to Theory of Mind competencies such as taking others' emotions, desires or beliefs into account, providing an "EASE ToM" score. The maximum score is 100. The EASE Social Skills and EASE ToM scales have a good internal consistency, with Cronbach's alphas of 0.77 and 0.79 respectively (Hughes et al., 1997).

Social Competence and Behavior Evaluation scale (SCBE, LaFrenière, Dumas, Capuano, \& Dubeau, 1992). This questionnaire evaluates social adjustment in children aged from 2.5 to 6 years. It can also be used to highlight externalized or internalized behavior problems. The parents of the child can complete this questionnaire and are asked to indicate the frequency and/or intensity of the behavior on a 6-point scale ranging from "never" to "always". This measure contains 80 items divided into eight subscales: depressive-joyful, anxious-secure, isolated-integrated, dependent-autonomous, angry-tolerant, aggressive-controlled, egotistical-prosocial and resistant-cooperative. These eight subscales can be gathered into four global scales, namely social competences, internalizing problems, externalizing problems and general adjustment. When the scores are converted into T-scores, difficulties or strengths on these scales can be identified. T-scores below 38 or above 68 reflect scores that are lower or higher than the mean scores observed in a representative sample. Cronbach's alpha for the different subscales of the French version of this questionnaire is between 0.79 and 0.82 .

Child Behavior Checklist (CBCL, Achenbach \& Edelbrock, 1991). This questionnaire of 79 items assesses referents' perception of children's behavioral and emotional problems. Externalized and internalized behavior are the two factors that stand out. The first factor is composed of two subscales, "attention problems" and "aggressive behavior", giving an externalized behavior score with a clinical cutoff at 24 . Four subscales, namely "anxious/depressed", "emotionally reactive", "withdrawn" and "somatic complaints" are integrated into the second factor, which determines an internalized behavior score with a clinical cutoff at 17. A final subscale concerns sleep problems. Parents of children aged from $1^{1 / 2}$ to 5 years old are asked to indicate the frequency of children's behavior on a 3-point scale (from "not at all present" to "often present"). Cronbach's alpha for the different subscales is between 0.63 and 0.86 .

\subsection{Results}

\subsubsection{Preliminary Analyses}

Table 3 presents means and standard deviations for social (mal)adjustment-related variables in children with IDs. 
Table 3. Means and standard deviations of participants' characteristics in Study 2.

\begin{tabular}{|c|c|c|c|}
\hline & & \multicolumn{2}{|c|}{ IDs sample } \\
\hline & & $M$ & SD \\
\hline \multicolumn{4}{|c|}{ Mothers characteristics $(\mathrm{n}=27)$} \\
\hline Educational level $(\max 8)$ & & 3.7 & 2.75 \\
\hline \multicolumn{4}{|l|}{ Fathers characteristics $(\mathrm{n}=16)$} \\
\hline Educational level (max 8) & & 4.08 & 3.31 \\
\hline \multicolumn{4}{|c|}{ Children's characteristics $(\mathrm{n}=27)$} \\
\hline Gender (\% male) & & $71 \%$ & \\
\hline \multirow[t]{2}{*}{ Age (in months) } & Chronological age & 103.15 & 24.87 \\
\hline & Developmental age & 59.26 & 16.24 \\
\hline \multirow[t]{5}{*}{ Social Adjustment } & EASE & 59.92 & 18.11 \\
\hline & EASE-ToM & 28.76 & 9.73 \\
\hline & EASE-Social Skills & 31.08 & 9.02 \\
\hline & SCBE-Social Competence & 109.40 & 26.35 \\
\hline & SCBE-General Adjustment & 245.76 & 45.99 \\
\hline \multirow[t]{4}{*}{ Social Maladjustment } & CBCL-Externalizing behavior & 16.42 & 12.23 \\
\hline & CBCL-Internalizing behavior & 18.29 & 9.64 \\
\hline & SCBE-Externalizing behavior & 65.57 & 17.94 \\
\hline & SCBE-Internalizing behavior & 70.79 & 15.71 \\
\hline \multirow[t]{8}{*}{ SCBE profile } & Depressive-Joyful & 35.42 & 8.48 \\
\hline & Anxious-Secure & 32.47 & 8.83 \\
\hline & Isolated-Integrated & 34.07 & 8.96 \\
\hline & Dependent-Autonomous & 27.77 & 8.51 \\
\hline & Angry-Tolerant & 26.06 & 8.20 \\
\hline & Aggressive-Controlled & 31.89 & 6.93 \\
\hline & Egotistical-Prosocial & 27.09 & 9.74 \\
\hline & Resistant-Cooperative & 30.99 & 9.02 \\
\hline
\end{tabular}

Notes. $M=$ mean, $S D=$ standard deviation, IDs = intellectual disabilities.

Regarding social adjustment and competences, the SCBE scores demonstrated that children with IDs had competences corresponding to those of a representative sample. This result was supported by the EASE scores, which also indicated that children with IDs had the same level of competences in social adjustment related to Theory of Mind or to social skills. Additionally, the SCBE scores showed that children with IDs had a profile similar to the mean scores obtained by a representative sample (namely T-scores ranging from 38 to 68 ). The lowest $\mathrm{T}$-scores (41 in each case) were obtained for the subscales autonomous-dependent and cooperative-resistant, implying that in their interactions with adults, these children were more dependent and more resistant to instructions than TD children. In terms of behavioral problems, the children display some internalizing problems at a clinical level, with a score higher than 17 for the CBCL. However, this result was not confirmed by the SCBE measure, where the children's mean T-score was 46 . The T-scores for externalizing behavior obtained in CBCL and SCBE (45) demonstrated that these children did not exhibit these kind of problems, at least at a clinical level. 
In order to explore the extent to which parents' emotion-related behaviors could predict the variance in the scores for social adjustment of children with IDs, linear regression analyses with a stepwise method were performed.

Before doing this, we checked the inter-correlations between the measures of parents' emotion-related behaviors and, first, individual characteristics of children with IDs (see Table 4), and second, social adjustment profiles of children with IDs, independently for mothers and fathers (see Table 5 and Table 6).

Table 4. Spearman correlations between the measures of parents' emotion-related behaviors and individual characteristics of children with IDs.

\begin{tabular}{|c|c|c|c|c|c|c|c|c|}
\hline & \multicolumn{3}{|c|}{ Individual characteristics of TD sample } & \multicolumn{5}{|c|}{ Individual characteristics of sample with IDs } \\
\hline & $\mathrm{CA}$ & GDA & SSE & $\mathrm{CA}$ & GDA & SES & CBCL-EB & CBCL-IB \\
\hline \multicolumn{9}{|l|}{ Mothers' behaviors } \\
\hline SUR_-E & -0.075 & -0.059 & -0.125 & -0.284 & -0.277 & 0.316 & -0.101 & 0.014 \\
\hline Comforting & -0.227 & -0.124 & -0.083 & $-0.504^{* *}$ & $-0.369^{\dagger}$ & 0.255 & -0.006 & 0.178 \\
\hline Problem-focused & $0.332^{\dagger}$ & $0.387^{*}$ & $0.349^{\dagger}$ & -0.089 & -0.097 & 0.279 & -0.015 & -0.195 \\
\hline Encouragement of expression of emotion & -0.124 & -0.219 & 0.065 & -0.117 & -0.285 & 0.064 & -0.157 & 0.320 \\
\hline NSUR_-E & -0.201 & 0.001 & -0.089 & 0.189 & -0.097 & -0.078 & -0.254 & -0.293 \\
\hline Distress & $-0.395^{\star}$ & $-0.325^{\dagger}$ & -0.165 & 0.210 & 0.005 & -0.033 & -0.232 & -0.307 \\
\hline Punitive & 0.040 & 0.137 & 0.066 & -0.041 & -0.222 & -0.085 & -0.108 & -0.029 \\
\hline Minimizing responses & -0.079 & 0.109 & -0.010 & 0.204 & -0.055 & 0.204 & -0.119 & -0.227 \\
\hline SUR_+E & -0.101 & -0.068 & -0.175 & 0.141 & -0.027 & 0.148 & -0.128 & 0.010 \\
\hline Socialization & 0.164 & 0.173 & -0.054 & 0.277 & 0.141 & 0.086 & -0.123 & -0.159 \\
\hline Encouragement & -0.073 & -0.081 & 0.069 & -0.122 & -0.161 & 0.032 & -0.082 & 0.288 \\
\hline NSUR_+E & -0.083 & -0.064 & -0.053 & $0.427^{\star}$ & 0.119 & 0.017 & -0.089 & -0.194 \\
\hline Reprimand & 0.036 & 0.093 & 0.153 & $0.413^{\star}$ & 0.196 & 0.040 & -0.085 & -0.244 \\
\hline Discomfort & -0.169 & -0.070 & -0.106 & $0.372^{\dagger}$ & 0.034 & -0.076 & -0.172 & -0.175 \\
\hline Emotion-related conversations & -0.203 & -0.214 & 0.057 & 0.205 & -0.026 & -0.121 & -0.189 & 0.036 \\
\hline \multicolumn{9}{|l|}{ Fathers' behaviors } \\
\hline SUR_-E & 0.065 & -0.106 & 0.161 & 0.287 & 0.157 & -0.247 & -0.302 & -0.345 \\
\hline Comforting & -0.243 & -0.351 & 0.072 & 0.390 & 0.368 & -0.471 & -0.388 & $-0.532^{\star}$ \\
\hline Problem-focused & 0.269 & 0.053 & -0.133 & 0.149 & 0.080 & -0.094 & -0.164 & -0.276 \\
\hline Encouragement of expression of emotion & 0.195 & 0.100 & 0.384 & 0.200 & 0.012 & -0.096 & -0.203 & -0.193 \\
\hline NSUR_-E & 0.389 & -0.257 & 0.344 & 0.217 & -0.238 & -0.224 & -0.128 & -0.091 \\
\hline Distress & -0.221 & -0.188 & -0.189 & 0.192 & -0.221 & -0.318 & -0.207 & -0.092 \\
\hline Punitive & -0.003 & 0.071 & -0.213 & 0.250 & -0.171 & -0.319 & -0.176 & -0.201 \\
\hline Minimizing responses & $-0.560^{*}$ & $-0.504^{\star}$ & -0.407 & 0.209 & -0.199 & 0.027 & 0.045 & 0.009 \\
\hline SUR_+E & 0.239 & 0.320 & 0.270 & 0.015 & -0.036 & 0.049 & 0.024 & -0.160 \\
\hline Socialization & 0.188 & 0.176 & 0.215 & -0.009 & -0.107 & -0.125 & 0.007 & -0.228 \\
\hline Encouragement & 0.221 & 0.230 & 0.175 & 0.085 & 0.123 & 0.210 & 0.052 & 0.014 \\
\hline NSUR_+E & 0.101 & 0.021 & -0.281 & -0.191 & -0.377 & -0.110 & -0.032 & 0.011 \\
\hline Reprimand & 0.098 & 0.012 & -0.338 & 0.060 & -0.197 & -0.005 & -0.090 & -0.056 \\
\hline Discomfort & -0.027 & 0.058 & 0.183 & -0.200 & -0.345 & -0.044 & 0.097 & 0.163 \\
\hline Emotion-related conversations & 0.279 & $0.547^{*}$ & 0.406 & -0.183 & -0.116 & -0.190 & -0.179 & -0.069 \\
\hline
\end{tabular}

Notes. SUR = supportive reactions, NSUR = unsupportive reactions, $-\mathrm{E}=$ negative emotion, $+\mathrm{E}=$ positive emotion, $\mathrm{TD}=$ typically developing, $\mathrm{IDs}=$ intel lectual disabilities, $\mathrm{CA}=$ chronological age, $\mathrm{GDA}=$ global developmental age, $\mathrm{SES}=$ socio-economic status, $\mathrm{EB}=$ externalizing behaviors, $\mathrm{IB}=$ internalizing behaviors ${ }^{\star} p<0.05,{ }^{* *} p<0.01$; ${ }^{* * *} p \leq 0.001$. 


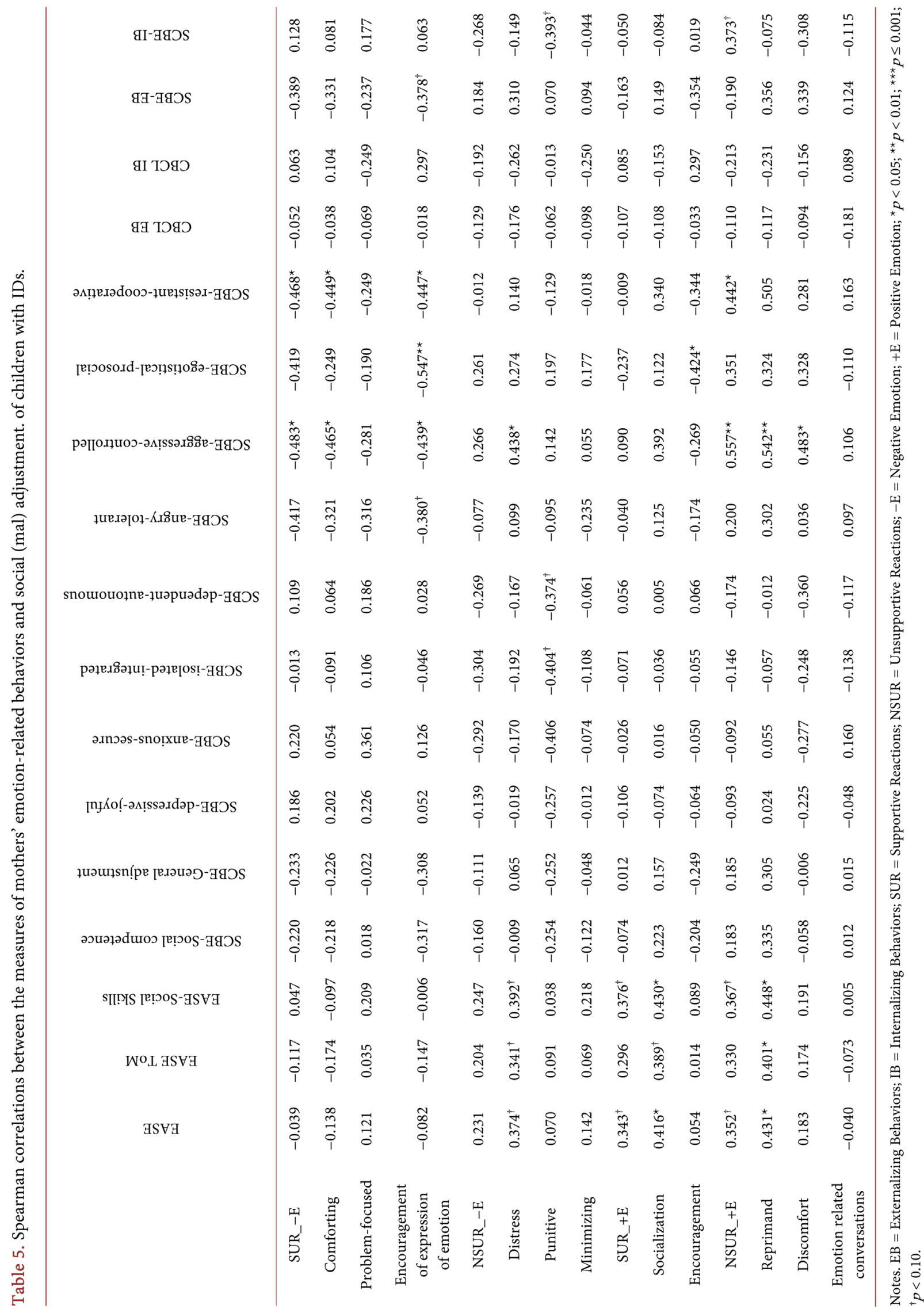




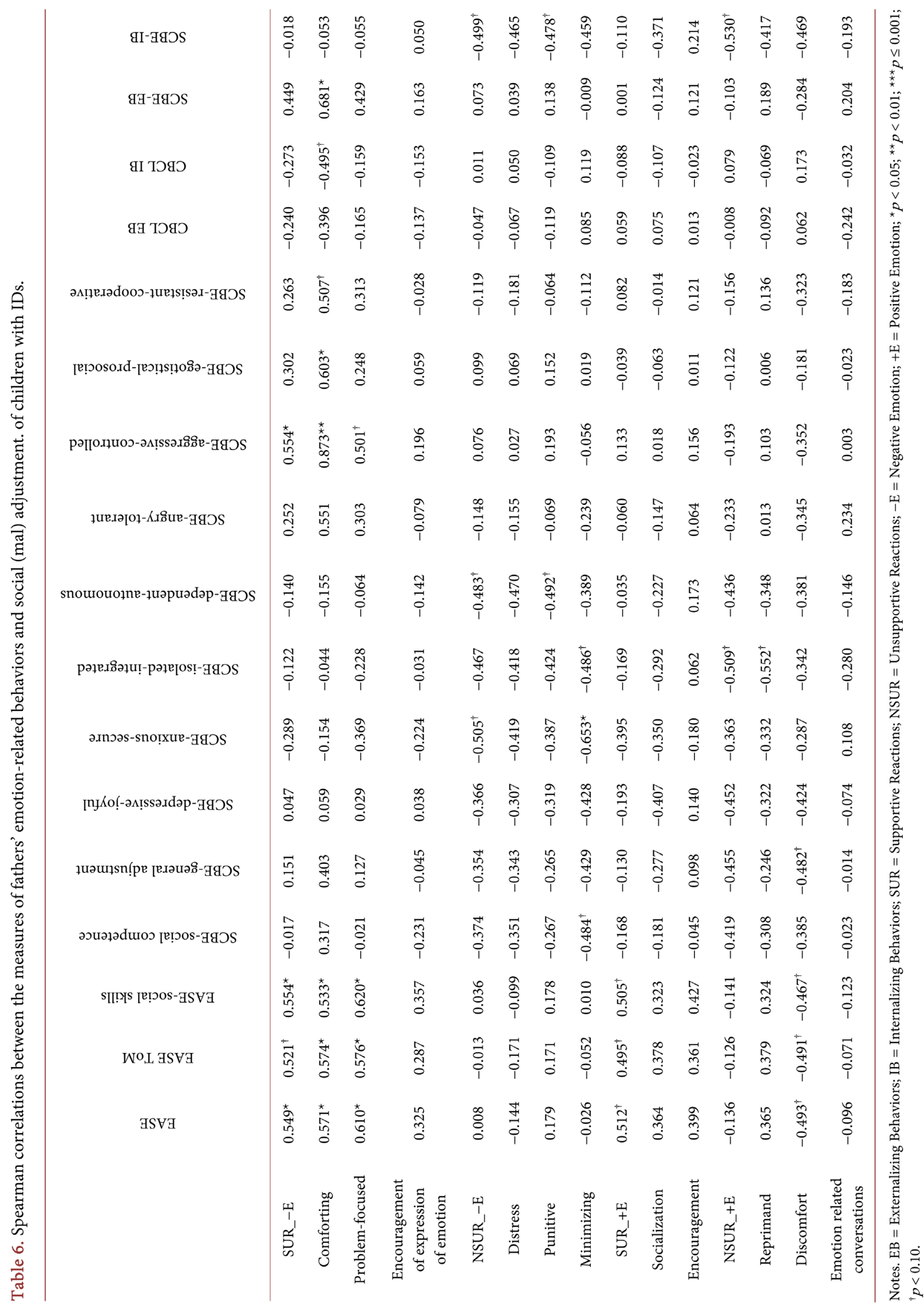




\subsubsection{Variability of Social (Mal)Adjustment of Children with Intellectual Disabilities According to Parents' Emotion-Related Behaviors}

Through linear regression analyses by the stepwise method, we explored the extent to which parents' emotion-related reactions or conversations could predict the variance in the scores for social (mal)adjustment. Two separate models were presented, for mothers' and fathers' emotion-related behaviors.

In Step 1, we entered the children's characteristics and chronological and developmental ages, and the level of education of their mothers or fathers. In Step 2 , we entered the parents' supportive and unsupportive reactions to negative and positive emotions. For the conversations, we entered the same variables in Step 1 and the total score of the questionnaire (QCPEE) in Step 2.

Multicollinearity was evaluated using the variance inflation index (VIF). In each group, for the two models (mothers and fathers), there was no multicollinearity between variables.

Mothers emotion-related behaviors with their children and social (mal)adjustment of children with IDs.

Table 7 presents the results of significant predictors of social (mal)adjustment of children with IDs.

GDA explained 32\%, 27\% and 34\% respectively of the variance in scores for social adjustment, including both the Theory of Mind and Social Skills subscores, in other words the scores of EASE, EASE-ToM and EASE-Social Skills. Moreover, $44 \%$ of the variance in social adjustment related to social skills (the EASE-Social Skills score) was explained by a Model M2c including GDA ( $\beta=$ $0.601 ; p \leq 0.001)$ and distress in response to negative emotions $(\beta=0.354 ; p<$ $0.05)$. Similarly, Model M2e, including GDA $(\beta=0.602 ; p \leq 0.01)$ and distress in response to negative emotions ( $\beta=0.392 ; p<0.05$ ), explained $47 \%$ of the variance in the general adjustment score obtained with the SCBE. For the SCBE scores for social competences and internalizing problems, $42 \%$ and $20 \%$ of the variance respectively was explained by GDA.

For the SCBE subscales, different variables explained the variance of profile. A Model M2g including GDA ( $\beta=0.609 ; p \leq 0.01)$ and problem-solving reactions to negative emotions $(\beta=0.408 ; p<0.05)$ explained $42 \%$ of the variance in the Anxious-Confident score. A Model M2h including CA $(\beta=0.539 ; p \leq 0.01)$ and distress reaction towards negative emotions $(\beta=0.448 ; p<0.05)$ explained $48 \%$ of the variance in the Aggressive-Controlled score. Distress reaction towards negative emotions explained $28 \%$ of the variance in the Egotistical-Prosocial score $(\beta=0.568 ; p<0.05)$. A Model M2j including CA $(\beta=0.428 ; p<0.05)$ and reprimanding reactions to positive emotions ( $\beta=0.431 ; p<0.05$ ) explained $44 \%$ of the variance in the Resistant-Cooperative score. Finally, $24 \%$ of the variance in the Dependent-Autonomous score was explained by GDA $(\beta=0.532 ; p<$ 0.05).

Concerning emotion-related conversations, $26 \%$ of the variance in the Isolated-Integrated score was explained by the number of joy-related terms used by 
Table 7. Predictors of mothers' reactions to children's (mal)adjustment profiles.

\begin{tabular}{|c|c|c|c|c|c|}
\hline \multicolumn{6}{|c|}{ Maternal Model } \\
\hline \multirow{2}{*}{ Predictors } & \multicolumn{5}{|c|}{ EASE-Total } \\
\hline & B & $\mathrm{SE} / \mathrm{B}$ & $\beta$ & $\mathrm{R}^{2}$ adj & $\mathrm{F}$ \\
\hline Model M1a & & & & 0.322 & $11.448^{\star *}$ \\
\hline \multirow[t]{2}{*}{ GDA } & 0.755 & 0.223 & $0.594^{* *}$ & & \\
\hline & \multicolumn{5}{|c|}{ EASE-ToM } \\
\hline Predictors & B & $\mathrm{SE} / \mathrm{B}$ & $\beta$ & $\mathrm{R}^{2}$ adj & $\mathrm{F}$ \\
\hline Model M1b & & & & 0.274 & $9.312^{* *}$ \\
\hline \multirow[t]{2}{*}{ GDA } & 0.376 & 0.123 & $0.544^{* *}$ & & \\
\hline & \multicolumn{5}{|c|}{ EASE-Social Skills } \\
\hline Predictors & B & $\mathrm{SE} / \mathrm{B}$ & $\beta$ & $\mathrm{R}^{2}$ adj & $\mathrm{F}$ \\
\hline Model M1c & & & & 0.336 & $12.120^{* *}$ \\
\hline GDA & 0.386 & 0.111 & $0.605^{\star *}$ & & \\
\hline Model M2c & & 0.102 & $0.601^{\star * *}$ & 0.440 & $9.656^{* *}$ \\
\hline GDA & 0.384 & & & & \\
\hline \multirow[t]{2}{*}{ Distress_-E } & 2.596 & 1.170 & $0.354^{*}$ & & \\
\hline & \multicolumn{5}{|c|}{ SCBE-Social Competences } \\
\hline Predictors & B & $\mathrm{SE} / \mathrm{B}$ & $\beta$ & $\mathrm{R}^{2}$ adj & $\mathrm{F}$ \\
\hline Model M1d & & & & 0.417 & $13.142^{* *}$ \\
\hline \multirow[t]{2}{*}{ GDA } & 1.142 & 0.315 & $0.672^{\star *}$ & & \\
\hline & \multicolumn{5}{|c|}{ SCBE-General Adjustment } \\
\hline Predictors & B & $\mathrm{SE} / \mathrm{B}$ & $\beta$ & $\mathrm{R}^{2}$ adj & $\mathrm{F}$ \\
\hline \multicolumn{6}{|l|}{ Model M1e } \\
\hline GDA & 1.749 & 0.560 & $0.616^{* *}$ & 0.340 & $9.765^{* *}$ \\
\hline \multicolumn{6}{|l|}{ Model M2e } \\
\hline GDA & 1.711 & 0.502 & $0.602^{\star *}$ & 0.470 & $8.551^{* *}$ \\
\hline Distress_-E & 12.500 & 5.627 & $0.392^{\star}$ & & \\
\hline & \multicolumn{5}{|c|}{ SCBE-Internalizing Problems } \\
\hline Predictors & B & $\mathrm{SE} / \mathrm{B}$ & $\beta$ & $\mathrm{R}^{2}$ adj & $\mathrm{F}$ \\
\hline Model M1f & & & & 0.198 & $5.197^{\star}$ \\
\hline \multirow[t]{2}{*}{ GDA } & 0.396 & 0.174 & $0.495^{\star}$ & & \\
\hline & \multicolumn{5}{|c|}{ SCBE-Anxious-Confident } \\
\hline Predictors & B & $\mathrm{SE} / \mathrm{B}$ & $\beta$ & $\mathrm{R}^{2}$ adj & $\mathrm{F}$ \\
\hline Model M1g & & & & 0.280 & $7.626^{\star}$ \\
\hline GDA & 0.309 & 0.112 & $0.568^{*}$ & & \\
\hline Model M2g & & & & 0.420 & $7.145^{\star *}$ \\
\hline GDA & 0.331 & 0.101 & $0.609^{\star *}$ & & \\
\hline Problem Solving_-E & 3.604 & 1.639 & $0.408^{*}$ & & \\
\hline
\end{tabular}




\section{Continued}

\begin{tabular}{|c|c|c|c|c|c|}
\hline \multirow[b]{2}{*}{ Predictors } & \multicolumn{5}{|c|}{ SCBE-Aggressive-Controlled } \\
\hline & B & $\mathrm{SE} / \mathrm{B}$ & $\beta$ & $\mathrm{R}^{2}$ adj & $\mathrm{F}$ \\
\hline Model M1h & & & & 0.306 & $8.489^{*}$ \\
\hline $\mathrm{CA}$ & 0.171 & 0.059 & $0.589^{*}$ & & \\
\hline Model M2h & & & & 0.485 & $8.996^{* *}$ \\
\hline $\mathrm{CA}$ & 0.156 & 0.051 & $0.539^{\star *}$ & & \\
\hline \multirow{2}{*}{ Distress_-E } & 2.210 & 0.863 & $0.448^{*}$ & & \\
\hline & \multicolumn{5}{|c|}{ SCBE-Egotistical-Prosocial } \\
\hline Predictors & B & $\mathrm{SE} / \mathrm{B}$ & $\beta$ & $\mathrm{R}^{2}$ adj & $\mathrm{F}$ \\
\hline Model M1i & & & & 0.280 & $7.614^{*}$ \\
\hline \multirow[t]{2}{*}{ Distress_-E } & 3.726 & 1.350 & $0.568^{*}$ & & \\
\hline & \multicolumn{5}{|c|}{ SCBE-Resistant-Cooperative } \\
\hline Predictors & B & $\mathrm{SE} / \mathrm{B}$ & $\beta$ & $\mathrm{R}^{2}$ adj & $\mathrm{F}$ \\
\hline Model M1j & & & & 0.303 & $8.380^{*}$ \\
\hline $\mathrm{CA}$ & 0.219 & 0.076 & $0.586^{*}$ & & \\
\hline Model M2j & & & & 0.439 & $7.639^{* *}$ \\
\hline $\mathrm{CA}$ & 0.160 & 0.073 & $0.428^{*}$ & & \\
\hline \multirow[t]{2}{*}{ Reprimand_+E } & 1.874 & 0.849 & $0.431^{*}$ & & \\
\hline & \multicolumn{5}{|c|}{ SCBE-Dependent-Autonomous } \\
\hline Predictors & B & $\mathrm{SE} / \mathrm{B}$ & $\beta$ & $\mathrm{R}^{2}$ adj & $\mathrm{F}$ \\
\hline Model M1k & & & & 0.238 & $6.319^{*}$ \\
\hline GDA & 0.250 & 0.100 & $0.532^{*}$ & & \\
\hline
\end{tabular}

Notes. $-\mathrm{E}=$ negative emotion, $+\mathrm{E}=$ positive emotion, $\mathrm{CA}=$ chronological age; $\mathrm{GDA}=$ global developmental age, ${ }^{*} p<0.05,{ }^{* *} p<0.01,{ }^{* * *} p \leq 0.001,{ }^{* * * *} p \leq 0.000$.

mothers $(\beta=-0.567 ; p<0.05)$, whereas $24 \%$ of the variance in the Egotistical-Prosocial score was explained by the number of emotion-related verbs used by mothers $(\beta=-0.547 ; p<0.05)$.

Fathers emotion-related behaviors with their children and social (mal) adjustment of children with IDs.

Table 8 presents the results of significant predictors of social (mal)adjustment of children with IDs.

Comforting reactions explained $39 \%$ and $44 \%$ respectively of the variance in scores for social adjustment, including the Theory of Mind subscore, in other words the scores of EASE $(\beta=0.667 ; p<0.05)$ and EASE-ToM $(\beta=0.701 ; p<$ $0.05)$. GDA explained $28 \%$ of the variance in social adjustment as related to social skills (the EASE-Social Skills subscore; $\beta=0.589 ; p<0.05$ ), and 39\%, $45 \%$ and $48 \%$ respectively of the variance in the social competences, general adjustment and internalizing problems scores obtained with the SCBE. 
Table 8. Predictors of fathers' reactions to children's (mal)adjustment profiles.

\begin{tabular}{|c|c|c|c|c|c|}
\hline \multicolumn{6}{|c|}{ Paternal Model } \\
\hline \multirow{2}{*}{ Predictors } & \multicolumn{5}{|c|}{ EASE-Total } \\
\hline & B & $\mathrm{SE} / \mathrm{B}$ & $\beta$ & $\mathrm{R}^{2}$ adj & $\mathrm{F}$ \\
\hline Model P1a & & & & 0.390 & $8.033^{*}$ \\
\hline \multirow[t]{2}{*}{ Comforting_-E } & 13.899 & 4.904 & $0.667^{*}$ & & \\
\hline & \multicolumn{5}{|c|}{ EASE-ToM } \\
\hline Predictors & B & $\mathrm{SE} / \mathrm{B}$ & $\beta$ & $\mathrm{R}^{2}$ adj & $\mathrm{F}$ \\
\hline Model P1b & & & & 0.441 & $9.678^{*}$ \\
\hline \multirow[t]{2}{*}{ Comforting_-E } & 8.530 & 2.742 & $0.701^{*}$ & & \\
\hline & \multicolumn{5}{|c|}{ EASE-Social Skills } \\
\hline Predictors & B & $\mathrm{SE} / \mathrm{B}$ & $\beta$ & $\mathrm{R}^{2}$ adj & $\mathrm{F}$ \\
\hline Model P1c & & & & 0.282 & $5.322^{*}$ \\
\hline \multirow[t]{2}{*}{ GDA } & 0.373 & 0.162 & $0.589^{*}$ & & \\
\hline & \multicolumn{5}{|c|}{ SCBE-Social Competences } \\
\hline Predictors & B & $\mathrm{SE} / \mathrm{B}$ & $\beta$ & $\mathrm{R}^{2}$ adj & $\mathrm{F}$ \\
\hline Model P1d & & & & 0.395 & $6.217^{\star}$ \\
\hline \multirow[t]{2}{*}{ GDA } & 1.503 & 0.603 & $0.686^{*}$ & & \\
\hline & \multicolumn{5}{|c|}{ SCBE-General Adjustment } \\
\hline Predictors & B & $\mathrm{SE} / \mathrm{B}$ & $\beta$ & $\mathrm{R}^{2}$ adj & $\mathrm{F}$ \\
\hline Model P1e & & & & 0.448 & $7.502^{*}$ \\
\hline \multirow[t]{2}{*}{ GDA } & 2.819 & 1.029 & $0.719^{*}$ & & \\
\hline & \multicolumn{5}{|c|}{ SCBE-Internalizing Problems } \\
\hline Predictors & B & $\mathrm{SE} / \mathrm{B}$ & $\beta$ & $\mathrm{R}^{2}$ adj & $\mathrm{F}$ \\
\hline Model P1f & & & & 0.481 & $8.427^{*}$ \\
\hline \multirow[t]{2}{*}{ GDA } & 0.810 & 0.279 & $0.739^{*}$ & & \\
\hline & \multicolumn{5}{|c|}{ SCBE-Depressive-Joyful } \\
\hline Predictors & B & $\mathrm{SE} / \mathrm{B}$ & $\beta$ & $\mathrm{R}^{2}$ adj & $\mathrm{F}$ \\
\hline Model P1g & & & & 0.628 & $14.517^{\star *}$ \\
\hline GDA & 0.644 & 0.169 & $0.821^{* *}$ & & \\
\hline Model P2g & & & & 0.800 & $16.989^{* *}$ \\
\hline GDA & 0.779 & 0.134 & $0.993^{* * *}$ & & \\
\hline \multirow[t]{2}{*}{ Reprimand_+E } & 3.324 & 1.256 & $0.452^{*}$ & & \\
\hline & \multicolumn{5}{|c|}{ SCBE-Anxious-Confident } \\
\hline Predictors & B & $\mathrm{SE} / \mathrm{B}$ & $\beta$ & $\mathrm{R}^{2}$ adj & $\mathrm{F}$ \\
\hline Model P1h & & & & 0.390 & $6.114^{*}$ \\
\hline \multirow[t]{2}{*}{ GDA } & 0.354 & 0.143 & $0.683^{*}$ & & \\
\hline & \multicolumn{5}{|c|}{ SCBE-Aggressive-Controlled } \\
\hline Predictors & B & $\mathrm{SE} / \mathrm{B}$ & $\beta$ & $\mathrm{R}^{2}$ adj & $\mathrm{F}$ \\
\hline Model P1i & & & & 0.691 & $18.893^{* *}$ \\
\hline Comforting_-E & 6.801 & 1.565 & $0.854^{* *}$ & & \\
\hline
\end{tabular}

Notes. $-\mathrm{E}=$ negative emotion, $+\mathrm{E}=$ positive emotion, $\mathrm{CA}=$ chronological age; $\mathrm{GDA}=$ global developmental age, ${ }^{*} p<0.05,{ }^{* *} p<0.01,{ }^{* *} p \leq 0.001$. 
For the subscales of SCBE, a Model P2g including GDA $(\beta=0.993 ; p<0.001)$ and reprimanding reactions to positive emotions $(\beta=0.452 ; p<0.05)$ explained $80 \%$ of the variance in the Depressive-Joyful score. GDA explained $39 \%$ of the variance in the Anxious-Confident score $(\beta=0.683 ; p<0.05)$. Finally, $69 \%$ of the variance in the Aggressive-Controlled score was explained by comforting reactions to negative emotions $(\beta=0.854 ; p \leq 0.01)$.

Regarding emotion-related conversations, no variable linked to QCPEE scores predicted the variance in social adjustment.

\section{Discussion}

Parenting a child with IDs can be challenging. Parents' ERSBs in this context may be different from those of parents of TD children. The impact of ERSBs may also be different, notably on children's social adjustment. Yet little is known about ERSBs in parents of children with IDs, or on their impact on child's social adjustment or maladjustment. For this reason, in a first study, this paper explored mothers' and fathers' ERSBs in interactions with their children with or without IDs, by investigating their reactions to their children's negative and positive emotions and their emotion-related conversations with them. A second study examined how mothers' and fathers' socialization of emotions induces variability in the social adjustment profiles of their children with IDs.

Regarding ERSBs of parents of children with IDs, they reported more unsupportive reactions than parents of TD children did. These findings were in line with those of Rodas et al. (2016), in which parents of children with IDs mentioned higher levels of unsupportive reactions. Parents of children with IDs reported notably a high level of discomfort with their children's positive emotions. This could be explained by the fact that these children expressed excessively positive emotions. Moreover, items that assessed discomfort presented social situations where calm behavior is expected (e.g. a ceremony in a church, a location where a baby is asleep). This context could exacerbate parents' frustration or embarrassment. In comparison to parents of TD children, mothers of children with IDs showed more punitive, minimizing and distress responses to children's negative emotions, while fathers of children with IDs displayed more distress. As it is related to parental stress, which is at a high level in these families (e.g. Baker et al., 2003; Hassall, Rose, \& McDonald, 2005; Nader-Grosbois \& Baurain, 2009), it is not surprising that distress is more reported by parents of children with IDs. Yet while this is an unsupportive strategy, it explained a part of the variance in social adjustment related to social skills and general adjustment, being associated in particular with a more controlled and prosocial profile of children with IDs. This unexpected result could be explained by the fact that items evaluating distress are on the one hand linked to social situations (e.g. "In a waiting room, parents felt ashamed at the crying of their child"; "Parents felt angry when their child had a temper tantrum over a toy in a supermarket"), and on the other hand associated with parents' anger and stress (e.g. "Parents felt upset because their 
child made a mistake due to not paying attention"; "Parents felt angry when their child acted like a baby by refusing to go to bed"). The expression of distress by parents in social situations seems to indicate to children that if they act in an inappropriate way, they will not be socially accepted, notably by their peers. Similarly, while it is an unsupportive reaction, reprimanding children for expressing positive emotions explained some features of children's social competences profile. In the maternal model, children's chronological age and reprimanding reactions explained the variance in the resistant-cooperative score: the older children were and the more their mothers used reprimanding responses, the more cooperative the children were with adults. By using reprimands, mothers seemed to encourage their children's ability to compromise or to ask for permission. In the fathers' model, a combination of children's global developmental age and the use of reprimands explained the variance in the depressive-joyful score: the higher the children's developmental age and the more their fathers used reprimands, the more children were perceived as joyful and good-tempered in daily life. These results underlined the importance of considering the potentially beneficial use of unsupportive strategies, as concluded by Denham (2007) or by Mazzone and Nader-Grosbois (2017b).

Concerning supportive reactions of parents of children with IDs, fathers utilized more comforting and problem-focused reactions and more encouragement of emotional expression than fathers of TD children did, whereas mothers only displayed more comforting reactions than mothers of TD children. The use of comforting, specifically by fathers, was observed to be beneficial for children with IDs. In the paternal model, the comforting reaction explained the variance in social adjustment, mostly related to Theory of Mind, and the variance in children's aggressive-controlled profile. This could imply that when fathers comfort their child, it helps them to understand others better and to develop good relationships, particularly with peers. Such a reaction may encourage children with IDs, provided they have reached a certain developmental age, to develop negotiation strategies and prosocial solutions. In contrast to fathers, mothers of children with IDs seemed to utilize the problem-focused reaction less than mothers of TD children. This observation supports that of Phillips et al. (2017), whose explanation was that mothers' reactions were more suited to their children's cognitive abilities in this respect. However, the results of Study $2 \mathrm{imp}$ ly that the use of these supportive reactions by mothers was positively related to a higher level of confidence in children. This parental strategy in mothers of children with IDs should therefore be supported during parental supervision or training.

Concerning emotion-related conversations, difference was only observed between mothers of children with or without IDs. Mothers of TD children reported more conversations about emotions than mothers of children with IDs; more precisely, mothers of TD children utilized more terms related to anger. This may be because mothers of children with IDs failed to spot opportunities to 
discuss emotions, in particular because of parental stress or their perception of their children's competences. Baker \& Crnic (2009) also observed that these parents focused less on emotions but tended to offer an efficient emotion socialization discourse.

In the interpretation of the results, some limitations have to be taken into account. At a methodological level, we lacked information about parents' age, although this could affect their ERSBs (Eisenberg et al., 1998). Moreover, although educational level of parents was been considered as a predictor in regression analyses, we could have added a measure of socio-Economic status, including family income. In this research we only assessed ERSBs with self-report measures. It would be interesting to add an observational measure, as used in the study of Rodas et al. (2016). The present study is part of a larger project that assesses the validity of an observational measure evaluating conversations about mental states (Jacobs \& Nader-Grosbois, 2017). As the heuristic model of the socialization of emotion (Eisenberg et al., 1998) describes ERSBs as consisting of parents' reactions and conversations, but also their emotional expressiveness, it would be interesting to add a measure of expressiveness. Mazzone and Nader-Grosbois (2017a) used a measure of Dimensions of Openness to Emotion developed by Reicherts (2007) with parents of children with autistic spectrum disorder. Given the numbers of studies investigating parental stress, this variable could be integrated into the method. Parental stress could have a moderating effect on the relation between ERSBs and children's social development. It also needs to be kept in mind that children with IDs had at greater risk to exhibit internalizing behavior problems (Baker et al., 2003; Dekker \& Koot, 2003; Dekker et al., 2002; Emerson, 2003; Merrell \& Holland, 1997; Nader-Grosbois et al., 2013; Thirion-Marissiaux \& Nader-Grosbois, 2008). In the present sample, children with IDs appeared to display this kind of behavioral problems, it is why it has to be considered when exploring the results. Moreover, because of the sample size, it would be interesting to replicate this study.

Despite these limitations, the major advantage of this research is the exploration of ERSBs in parents in response to negative and positive emotions of their children with IDs. The results highlight a difference in parents of children with or without IDs and the importance of considering this disparity in parents' interventions. As professionals, it is particularly crucial to keep this difference in mind but also to spread a non-dichotomous vision of ERSBs. Sometimes, parenting described as unsupportive for TD children may be wholly appropriate for children with IDs: the present results indicate a potentially beneficial effect of parental distress on children's social adjustment and of reprimand on social competences. However, the impact on social profile is explained not just by ERSBs but also by children's individual characteristics. Parents of children with IDs seem to adapt their ERSBs to their children's profiles. Moreover, depending on their personal style or personality, mothers and fathers contribute differently to their children's social development (Baker, Fenning, \& Crnic, 2011; Eisenberg et al., 1996; Rodas et al., 2017). In parenting support programs, professionals 
should support different ERSBs in mothers and fathers. The present research points out that problem-focused reaction should be boosted in mothers while comforting should be promoted in fathers.

Parenting programs should take account of the difference between mothers and fathers and the specific cognitive, emotional and social profile of children with IDs. Professionals need to underline this difference and emphasize the specific characteristics of children with IDs in terms of weaknesses and strengths. They should also promote a positive vision of all ERSBs. In parenting programs such as the Tuning into Kids program (Havighurst \& Harley, 2007), the authors underline the importance of not overburdening parents by telling them what to do. By adopting a positive psychology-related vision, professionals can support the strengths of parents and therefore maintain their resilience.

\section{Acknowledgements}

We wish to thank the Marguerite-Marie Delacroix Foundation for its financial support for this research. We are also grateful to the Chair Baron Frère for its support and to all the parents and children who took part in this research.

\section{Conflicts of Interest}

The authors declare no conflicts of interest regarding the publication of this paper.

\section{References}

AAIDD (2011). Déficience intellectuelle. Définition, classification et systèmes de soutien. Paper presented at the Consortium national de recherche sur l'intégration sociale, Trois-Rivières, Canada.

Achenbach, T. M., \& Edelbrock, C. (1991). Child Behavior Checklist. Burlington (Vt), 7.

Baker, B. L., McIntyre, L. L., Blacher, J., Crnic, K. A., Edelbrock, C., \& Low, C. (2003). Pre-School Children with and without Developmental Delay: Behaviour Problems and Parenting Stress over Time. Journal of Intellectual Disability Research, 47, 217-230. https://doi.org/10.1046/j.1365-2788.2003.00484.x

Baker, B. L., Neece, C. L., Fenning, R. M., Crnic, K. A., \& Blacher, J. (2010). Mental Disorders in Five-Year-Old Children with or without Developmental Delay: Focus on ADHD. Journal of Clinical Child \& Adolescent Psychology, 39, 492-505. https://doi.org/10.1080/15374416.2010.486321

Baker, J. K., \& Crnic, K. A. (2009). Thinking about Feelings: Emotion Focus in the Parenting of Children with Early Developmental Risk. Journal of Intellectual Disability Research, 53, 450-462. https://doi.org/10.1111/j.1365-2788.2009.01161.x

Baker, J. K., Fenning, R. M., \& Crnic, K. A. (2011). Emotion Socialization by Mothers and Fathers: Coherence among Behaviors and Associations with Parent Attitudes and Children's Social Competence. Social Development, 20, 412-430. https://doi.org/10.1111/j.1467-9507.2010.00585.x

Baurain, C., \& Nader-Grosbois, N. (2013). Theory of Mind, Socio-Emotional Problem-Solving, Socio-Emotional Regulation in Children with Intellectual Disability and in Typically Developing Children. Journal of Autism and Developmental Disorders, 43, 1080-1097. https://doi.org/10.1007/s10803-012-1651-4 
Bougher-Muckian, H. R., Root, A. E., Coogle, C. G., \& Floyd, K. K. (2016). The Importance of Emotions: The Socialisation of Emotion in Parents of Children with Autism Spectrum Disorder. Early Child Development and Care, 186, 1584-1593. https://doi.org/10.1080/03004430.2015.1112799

Casey, R. J., \& Fuller, L. L. (1994). Maternal Regulation of Children's Emotions. Journal of Nonverbal Behavior, 18, 57-89. https://doi.org/10.1007/BF02169079

Chorpita, B. F., \& Barlow, D. H. (1998). The Development of Anxiety: The Role of Control in the Early Environment. Psychological Bulletin, 124, 3. https://doi.org/10.1037/0033-2909.124.1.3

Coutu, S., Dubeau, D., Provost, M., Royer, N., \& Lavigueur, S. (2002). Validation de la version française du questionnaire: Coping with Children's Negative Emotions Scale-CCNES. Canadian Journal of Behavioural Science, 34, 230-234. https://doi.org/10.1037/h0087175

Crnic, K. A., Hoffman, C., Gaze, C., \& Edelbrock, C. (2004). Understanding the Emergence of Behavior Problems in Young Children with Developmental Delays. Infants \& Young Children, 17, 223-235. https://doi.org/10.1097/00001163-200407000-00004

Daffe, V., \& Nader-Grosbois, N. (2009). Parental Reactions toward Their Children's Emotions: Combined Version of Two Questionnaires. In N. Nader-Grosbois (Ed.), Resilience, Regulation and Quality of Life (pp. 143-159). Louvain-la-Neuve: Presses Universitaires de Louvain.

Degnan, K. A., Almas, A. N., \& Fox, N. A. (2010). Temperament and the Environment in the Etiology of Childhood Anxiety. Journal of Child Psychology and Psychiatry, 51, 497-517. https://doi.org/10.1111/j.1469-7610.2010.02228.x

Dekker, M. C., \& Koot, H. M. (2003). DSM-IV Disorders in Children with Borderline to Moderate Intellectual Disability. I: Prevalence and Impact. Journal of the American Academy of Child \& Adolescent Psychiatry, 42, 915-922. https://doi.org/10.1097/01.CHI.0000046892.27264.1A

Dekker, M. C., Koot, H. M., Ende, J. V. D., \& Verhulst, F. C. (2002). Emotional and Behavioral Problems in Children and Adolescents with and without Intellectual Disability. Journal of Child Psychology and Psychiatry, 43, 1087-1098. https://doi.org/10.1111/1469-7610.00235

Denham, S. A. (2007). Dealing with Feelings: How Children Negotiate the Worlds of Emotions and Social Relationships. Cognition, Brain, Behavior, 11, 1.

Denham, S. A., Bouril, B., \& Belouad, F. (1994). Preschoolers' Affect and Cognition about Challenging Peer Situations. Child Study Journal, 24, 1-21.

Dodge, K. A., \& Pettit, G. S. (2003). A Biopsychosocial Model of the Development of Chronic Conduct Problems in Adolescence. Developmental Psychology, 39, 349. https://doi.org/10.1037/0012-1649.39.2.349

Eisenberg, N., Cumberland, A., \& Spinrad, T. L. (1998). Parental Socialization of Emotion. Psychological Inquiry, 9, 241-273. https://doi.org/10.1207/s15327965pli0904_1

Eisenberg, N., Fabes, R. A., \& Murphy, B. C. (1996). Parents' Reactions to Children's Negative Emotions: Relations to Children's Social Competence and Comforting Behavior. Child Development, 67, 2227-2247. https://doi.org/10.2307/1131620

Eisenberg, N., Fabes, R. A., Shepard, S. A., Guthrie, I. K., Murphy, B. C., \& Reiser, M. (1999). Parental Reactions to Children's Negative Emotions: Longitudinal Relations to Quality of Children's Social Functioning. Child Development, 70, 513-534. https://doi.org/10.1111/1467-8624.00037

Emerson, E. (2003). Prevalence of Psychiatric Disorders in Children and Adolescents with 
and without Intellectual Disability. Journal of Intellectual Disability Research, 47, 51-58. https://doi.org/10.1046/j.1365-2788.2003.00464.x

Fabes, R. A., Eisenberg, N., \& Bernzweig, J. (1990). The Coping with Children's Negative Emotions Scale: Procedures and Scoring. Tempe, AZ: Arizona State University. https://doi.org/10.1037/t36591-000

Fabes, R. A., Eisenberg, N., Karbon, M., Bernzweig, J., Lee Speer, A., \& Carlo, G. (1994). Socialization of Children's Vicarious Emotional Responding and Prosocial Behavior: Relations with Mothers' Perceptions of Children's Emotional Reactivity. Developmental Psychology, 30, 44-55. https://doi.org/10.1037/0012-1649.30.1.44

Fabes, R. A., Leonard, S. A., Kupanoff, K., \& Martin, C. L. (2001). Parental Coping with Children's Negative Emotions: Relations with Children's Emotional and Social Responding. Child Development, 72, 907-920. https://doi.org/10.1111/1467-8624.00323

Fabes, R. A., Poulin, R. E., Eisenberg, N., \& Madden-Derdich, D. A. (2002). The Coping with Children's Negative Emotions Scale (CCNES): Psychometric Properties and Relations with Children's Emotional Competence. Marriage \& Family Review, 34, 285-310. https://doi.org/10.1300/J002v34n03_05

Gascon, H., Bibeau, M.-J., Grondin, J., \& Milot, É. (2010). Chapitre 3. Bien-être psychologique des élèves adolescents présentant un retard mental léger. In M.-C. Haelewyck, \& H. Gascon (Eds.), Adolescence et retard mental (pp. 49-59). Louvain-laNeuve: De Boeck Supérieur. https://doi.org/10.3917/dbu.haele.2010.01

Gottman, J. M., Katz, L. F., \& Hooven, C. (1996). Parental Meta-Emotion Philosophy and the Emotional Life of Families: Theoretical Models and Preliminary Data. Journal of Family Psychology, 10, 243-268. https://doi.org/10.1037/0893-3200.10.3.243

Hassall, R., Rose, J., \& McDonald, J. (2005). Parenting Stress in Mothers of Children with an Intellectual Disability: The Effects of Parental Cognitions in Relation to Child Characteristics and Family Support. Journal of Intellectual Disability Research, 49, 405-418. https://doi.org/10.1111/j.1365-2788.2005.00673.x

Hauser-Cram, P., \& Woodman, A. C. (2016). Trajectories of Internalizing and Externalizing Behavior Problems in Children with Developmental Disabilities. Journal of $A b$ normal Child Psychology, 44, 811-821. https://doi.org/10.1007/s10802-015-0055-2

Havighurst, S., \& Harley, A. (2007). Tuning in to Kids: Emotionally Intelligent Parenting: Program Manual. Melbourne: University of Melbourne.

Hudson, J. L., \& Rapee, R. M. (2001). Parent-Child Interactions and Anxiety Disorders: An Observational Study. Behaviour Research and Therapy, 39, 1411-1427. https://doi.org/10.1016/S0005-7967(00)00107-8

Hughes, C., Soares-Boucaud, I., Hochmann, J., \& Frith, U. (1997). Social Behaviour in Pervasive Developmental Disorders: Effects of Informant, Group and “Theory-of-Mind”. European Child \& Adolescent Psychiatry, 6, 191-198. https://doi.org/10.1007/s007870050029

Jacobs, E., \& Nader-Grosbois, N. (2017). Grille de Conversations autour des états mentaux Parent-Enfant. Louvain-La-Neuve: UCLOUVAIN.

Jones, S., Eisenberg, N., Fabes, R. A., \& MacKinnon, D. P. (2002). Parents' Reactions to Elementary School Children's Negative Emotions: Relations to Social and Emotional Functioning at School. Merrill-Palmer Quarterly, 48, 133-159.

https://doi.org/10.1353/mpq.2002.0007

Kasari, C., \& Bauminger, N. (1998). Social and Emotional Development in Children with Mental Retardation. In J. Burack., R. M. Hodapp, \& E. Zigler (Eds.), Handbook of Mental Retardation and Development (pp. 411-433). New York: Cambridge University Press. 
Keogh, B. K., Bernheimer, L. P., Daley, S., \& Haney, M. (1989). Behaviour and Adjustment Problems of Young Developmentally Delayed Children. European Journal of Special Needs Education, 4, 79-90. https://doi.org/10.1080/0885625890040201

Ladouceur, C., Reid, L., \& Jacques, A. (2002). Construction et validation du Questionnaire sur les réactions parentales aux émotions positives exprimées par l'enfant. Canadian Journal of Behavioural Science, 34, 8-18. https://doi.org/10.1037/h0087150

LaFrenière, P. J., Dumas, J. E., Capuano, F., \& Dubeau, D. (1992). Development and Validation of the Preschool Socioaffective Profile. Psychological Assessment, 4, 442-450. https://doi.org/10.1037/1040-3590.4.4.442

Lagattuta, K. H., \& Wellman, H. M. (2002). Differences in Early Parent-Child Conversations about Negative versus Positive Emotions: Implications for the Development of Psychological Understanding. Developmental Psychology, 38, 564.

https://doi.org/10.1037/0012-1649.38.4.564

Mazzone, S., \& Nader-Grosbois, N. (2017a). Emotion-Related Socialization Behaviours in Parents of Children with an Autism Spectrum Disorder. Psychology, 8, 1134-1160. https://doi.org/10.4236/psych.2017.88074

Mazzone, S., \& Nader-Grosbois, N. (2017b). Variability and Predictors of Mothers and Fathers' Socialization Behaviors and Bidirectional Links with Their Preschoolers Socio-Emotional Competences. Journal of Behavioral and Brain Science, 7, 621-653. https://doi.org/10.4236/jbbs.2017.712043

Mazzone, S., Roskam, I., Mikolajczak, M., \& Nader-Grosbois, N. (2017). Do Parents Talk about Emotions with Their Children? The Questionnaire of Parent-Child Conversations about Emotions (QPCCE). Psychology, 8, 987-1007. https://doi.org/10.4236/psych.2017.87065

McIntyre, L. L. (2008). Parent Training for Young Children with Developmental Disabilities: Randomized Controlled Trial. American Journal on Mental Retardation, 113, 356-368. https://doi.org/10.1352/2008.113:356-368

McKee, L., Roland, E., Coffelt, N., Olson, A. L., Forehand, R., Massari, C., \& Zens, M. S. (2007). Harsh Discipline and Child Problem Behaviors: The Roles of Positive Parenting and Gender. Journal of Family Violence, 22, 187-196.

https://doi.org/10.1007/s10896-007-9070-6

Merrell, K. W., \& Holland, M. L. (1997). Social-Emotional Behavior of Preschool-Age Children with and without Developmental Delays. Research in Developmental Disabilities, 18, 393-405. https://doi.org/10.1016/S0891-4222(97)00018-8

Nader-Grosbois, N., \& Baurain, C. (2009). Stress and Resilience in Families with Atypical Children. In N. Nader-Grosbois (Ed.), Resilience, Regulation and Quality of Life (pp. 107-119). Louvain-la-Neuve: Presses Universitaires de Louvain.

Nader-Grosbois, N., Houssa, M., \& Mazzone, S. (2013). How Could Theory of Mind Contribute the Differentiation Social Adjustment Profiles of Children with Externalizing Behavior Disorders and Children with Intellectual Disabilities? Research in Developmental Disabilities, 34, 2642-2660. https://doi.org/10.1016/j.ridd.2013.05.010

Paczkowski, E., \& Baker, B. L. (2007). Parenting Children with and without Developmental Delay: The Role of Self-Mastery. Journal of Intellectual Disability Research, 51, 435-446. https://doi.org/10.1111/j.1365-2788.2006.00894.x

Phillips, B. A., Conners, F., \& Curtner-Smith, M. E. (2017). Parenting Children with Down Syndrome: An Analysis of Parenting Styles, Parenting Dimensions, and Parental Stress. Research in Developmental Disabilities, 68, 9-19.

https://doi.org/10.1016/j.ridd.2017.06.010

Reicherts, M. (2007). Dimensions of Openness to Emotions (DOE): A Model of Affect 
Processing. Manual. Fribourg: Department of Psychology, University of Fribourg.

Robinson, C., Mandleco, B., Olsen, S. F., \& Hart, C. (2001). The Parenting Styles and Dimensions Questionnaire (PSDQ). In B. F. Perlmutter, J. Touliatos, \& G. W. Holden (Eds.), Handbook of Family Measurement Techniques: Vol. 3. Instruments \& Index (pp. 319-321). Thousand Oaks, CA: Sage.

Rodas, N. V., Chavira, D. A., \& Baker, B. L. (2017). Emotion Socialization and Internalizing Behavior Problems in Diverse Youth: A Bidirectional Relationship across Childhood. Research in Developmental Disabilities, 62, 15-25. https://doi.org/10.1016/j.ridd.2017.01.010

Rodas, N. V., Zeedyk, S. M., \& Baker, B. L. (2016). Unsupportive Parenting and Internalising Behaviour Problems in Children with or without Intellectual Disability. Journal of Intellectual Disability Research, 60, 1200-1211. https://doi.org/10.1111/jir.12332

Rubin, K. H., \& Mills, R. S. (1991). Conceptualizing Developmental Pathways to Internalizing Disorders in Childhood. Canadian Journal of Behavioural Science, 23, 300-317. https://doi.org/10.1037/h0079019

Schuiringa, H., van Nieuwenhuijzen, M., Orobio de Castro, B., \& Matthys, W. (2015). Parenting and the Parent-Child Relationship in Families of Children with Mild to Borderline Intellectual Disabilities and Externalizing Behavior. Research in Developmental Disabilities, 36, 1-12. https://doi.org/10.1016/j.ridd.2014.08.018

Taylor, J. (2002). A Review of the Assessment and Treatment of Anger and Aggression in Offenders with Intellectual Disability. Journal of Intellectual Disability Research, 46, 57-73. https://doi.org/10.1046/j.1365-2788.2002.00005.x

Thirion-Marissiaux, A.-F., \& Nader-Grosbois, N. (2008). Theory of Mind and Socio-Affective Abilities in Disabled Children and Adolescents. European Journal of Disability Research, 2, 133-155. https://doi.org/10.1016/j.alter.2008.02.003

Wechsler, D. (2004). Echelle d'intelligence de Wechsler pour la période préscolaire et primaire (Vol. 3). Paris: Paris Les éditions du Centre de Psychologie appliquée.

Wong, M. S., McElwain, N. L., \& Halberstadt, A. G. (2009). Parent, Family, and Child Characteristics: Associations with Mother- and Father-Reported Emotion Socialization Practices. Journal of Family Psychology, 23, 452-463. https://doi.org/10.1037/a0015552

Zion, E., \& Jenvey, V. (2006). Temperament and Social Behaviour at Home and School among Typically Developing Children and Children with an Intellectually Disability. Journal of Intellectual Disability Research, 50, 445-456. https://doi.org/10.1111/j.1365-2788.2006.00790.x 